\title{
Peritoneal Dialysis in the Pediatric Intensive Care Unit Setting: Techniques, Quantitations and Outcomes
}

\author{
Melvin Bonilla-Félix \\ Department of Pediatrics, University of Puerto Rico - Medical Sciences Campus, San Juan, P.R., USA
}

\section{Key Words}

Peritoneal dialysis • Intensive care unit - Acute kidney injury $\cdot$ Children $\cdot$ Infants

\begin{abstract}
Acute kidney injury (AKI) is a common complication in pediatric and neonatal intensive care units (ICU). Renal replacement therapy (RRT) is frequently needed in children in whom supportive therapy is not enough to satisfy their metabolic demands or to be able to provide adequate nutrition. The decision to begin dialysis should not be delayed since experience in infants shows that the shorter the time from the insult to the beginning of dialysis, the higher the survival rate. As the use of continuous RRT in pediatric patients in the ICU has almost tripled, the use of peritoneal dialysis (PD) and intermittent hemodialysis has markedly decreased. The patient's age seems to be the most important factor influencing the decision on the choice of dialysis modality. PD is still the most common modality used in patients younger than 6 years of age. The relatively low cost, technical simplicity, no need for anticoagulation or placement of central venous catheters, and excellent tolerance in hemodynamically unstable patients are among the most significant advantages of PD. Much controversy exists regarding the adequacy of PD in hypercatabolic patients in the ICU. Nonetheless, when
\end{abstract}

$\mathrm{Kt} / \mathrm{V}$ has been applied to acutely ill children, it has been shown that PD can provide adequate clearances for most infants. The outcomes of critically ill patients with AKI treated with PD are comparable to other dialysis modalities. Therefore, the decision about dialysis modality should be based on local expertise, resources available, and patient's clinical status.

Copyright $\odot 2013$ S. Karger AG, Basel

\section{Acute Kidney Injury in the Pediatric Intensive Care Units}

Acute kidney injury (AKI) is observed in $3-5 \%$ of patients admitted to the intensive care unit (ICU). It is associated with an overall mortality rate between 20 and $30 \%$, but it is much higher in children with multiorgan failure requiring mechanical ventilation. Despite significant advances in the use of renal replacement therapy (RRT) in children with AKI, the mortality has not changed over the last two decades, probably as a result of changes in its epidemiology [1]. Although infectious diseases such as diarrhea, malaria and hemolytic uremic syndrome are still the major cause of pediatric AKI in developing countries, ischemia is the leading cause in the developed countries $[2,3]$. As the survival of children

\section{KARGER}

Fax +4161306 1234

E-Mail karger@karger.ch

www.karger.com (c) 2013 S. Karger AG, Basel

0253-5068/13/0353-0077\$38.00/0

Accessible online at:

www.karger.com/bpu
Prof. Melvin Bonilla-Félix, MD

Department of Pediatrics

University of Puerto Rico - Medical Sciences Campus

PO Box 365067, San Juan, PR 00936-5067 (USA)

E-Mail melvin.bonilla1@upr.edu 
with previously considered fatal disorders has improved, the disease severity of pediatric patients with AKI has also increased due to the presence of comorbidities. AKI is more prevalent in hospitalized children with multiorgan involvement. The leading causes are ischemia secondary to cardiovascular surgery for correction of complicated cardiac anomalies, sepsis, or the use of nephrotoxic drugs. Severe congenital anomalies of the urinary tract including obstructive uropathies, hypoplasia/dysplasia and autosomal recessive polycystic kidneys can present as AKI in the newborn period, even when they often lead to chronic kidney disease. Primary renal disorders such as acute glomerulonephritis, connective tissue disorders and vasculitis are more prevalent in older children.

Even small increases in serum creatinine levels predict the development of AKI and are associated with increased mortality and hospital stay in children and adults in ICU $[4,5]$. It has become evident that, in addition to the immediate life threat that AKI represents to an ICU patient, the long-term consequences can also be very serious and not as favorable as previously thought. In a population of patients who developed AKI in a tertiary pediatric ICU, up to $10 \%$ developed chronic kidney disease $1-3$ years after AKI, suggesting that long-term follow-up of these patients is mandatory [6].

\section{Indications and Choice of Modality}

RRT is frequently needed in children in whom supportive therapy is not enough to satisfy their metabolic demands or to be able to provide adequate nutrition. The decision to start dialysis should not be delayed as the survival rate is better if dialysis is started earlier [7]. In neonates and infants with AKI following cardiac surgery, beginning peritoneal dialysis (PD) within the first $24 \mathrm{~h}$ after surgery was associated with a 47 and $44 \%$ decrease in 30 and 90-day mortality, respectively [8]. One of the most important parameters that should be monitor closely is the degree of fluid overload. Children who had more than $20 \%$ of fluid overload at the beginning of continuous RRT (CRRT) had more than twice the mortality than those commencing CRRT with less than 10\% fluid overload [9].

The pediatric nephrologist is frequently faced with the question of which form of RRT best fits the needs of his critically ill patients. Over the last decade there has been a decreasing trend in the use of PD and intermittent hemodialysis, as the use of CRRT in pediatric patients in the ICU has almost tripled. The patient's age seems to be the most critical factor influencing the decision of the nephrologists on the choice of dialysis modality [10]. Although overall, pediatric nephrologists report CRRT as their preferred dialysis modality for acutely ill children, PD is still the most common modality used in patients younger than 6 years of age. Particularly, it has a prominent role in the treatment of small infants admitted to the intensive cardiovascular unit after surgery for congenital heart defects [10].

Among the several advantages that PD offers, the relatively low cost is probably the most significant. A cost analysis demonstrated that $\mathrm{PD}$ is the most inexpensive of all renal replacement therapies. The cost benefit is more remarkable when manual exchanges are used since it eliminates the significant cost associated with the purchase of an automated machine [11]. This represents an attractive alternative for centers in developing countries with limited resources. Nonetheless, if the infant's weight and resources permit, use of an automated cycler is preferable as manual PD is potentially associated with higher risk of infections. Other advantages include the technical simplicity (particularly with manual exchanges), no need for anticoagulation or placement of central venous catheters, and excellent tolerance in hemodynamically unstable patients. Some have said that the peritoneum is the most 'biocompatible' of all the dialysis membranes available. Conversely, the major limitations of PD in the ICU setting are the slow and inefficient nature of the treatment, which precludes its use in children with severe lifethreatening pulmonary edema and hyperkalemia, and the need for surgery to place a PD catheter.

\section{Techniques}

Placement of a tunneled Tenckhoff catheter is preferred to prevent technical complications such as leaks and catheter obstruction [12]. Nevertheless, percutaneous catheters are a viable option in unstable children who cannot tolerate surgery or if a surgeon is not available. A new technique using a multipurpose percutaneous catheter has shown promising results with complication rates comparable to Tenckhoff catheters [13].

Although the use of automated cyclers provides a precise measurement of ultrafiltration, manual exchanges are inexpensive, technically simple and can provide an efficient form of dialysis if an automated machine is not available, and in small infants in whom the starting exchange volume is below the minimal permitted by the cycler. The technique for manual exchanges is so simple 
that the specialized PD nurse can teach the ICU nurses to perform manual exchanges quickly, which avoids the continuous need of a specialized dialysis nurse at the bedside.

The dialysis prescription should be adjusted according to patient's needs. Basic principles include the use of frequent, continuous exchanges, with low volumes of dialysate. Therapy should be initiated with low volumes in the range of $10-20 \mathrm{ml} / \mathrm{kg}$ of body weight $\left(300-600 \mathrm{ml} / \mathrm{m}^{2}\right)$. This may prevent dialysate leakage and respiratory complications from compression of lungs, while providing adequate ultrafiltration rates in critically ill children [14]. Heparin at a dose of $250-500 \mathrm{U} / \mathrm{l}$ of PD fluid is frequently used initially to prevent clots from bloody PD fluid or strands of fibrin. Dwell times are usually kept between 40 and 60 min per exchange to ensure adequate ultrafiltration rates. Infants younger than 12 months may need dwell times as short as 20 min to maintain effective ultrafiltration. However, this carries a risk of sodium sieving [15]. As fluid overload is one of the most common indications for acute $\mathrm{PD}$, it is usually recommended to start PD therapy using previously warmed peritoneal fluid with a glucose concentration of $2.5 \mathrm{~g} / 100 \mathrm{ml}(2.5 \%)$. After a few exchanges, the solution can be switched to $4.25 \%$ if more efficient ultrafiltration is required, or to $1.5 \%$ if the patient is euvolemic or hemodynamically unstable. Use of PD fluid with high glucose concentration can lead to significant hyperglycemia. If PD is used continuously for several days, hypokalemia may develop, requiring addition of $\mathrm{KCl}$ to the PD fluid at a concentration of 3-4 $\mathrm{mEq} / \mathrm{l}$ to maintain normokalemia [16].

\section{Quantitation}

Much controversy exists regarding the adequacy of $\mathrm{PD}$ in hypercatabolic patients in the ICU. The definition of adequate dialysis in patients with $\mathrm{AKI}$ is far from clear. In principle, adequate dialysis should be defined as the RRT that makes the patient's clinical condition improve. Therefore, if the hemodynamic status is improving (evaluated by the need of inotropic agents), the edema is resolving, the ultrafiltration rates obtained are sufficient to provide adequate nutrition, and the metabolic parameters are improving (serum electrolytes, serum creatinine and blood urea nitrogen levels), the patient is receiving adequate dialysis. One has to be cautious when applying parameters such as the urea kinetic model to define adequacy of dialysis in patients in the ICU setting who frequently have multiorgan failure, lack a steady state, have frequent shifts in volume status, and are hypercatabolic. Nonetheless, when Kt/V has been applied to acutely ill children, it has been shown that $\mathrm{PD}$ can provide Kt/V values $>2.1$ for most infants [17]. The use of tidal PD can provide better clearances, but is associated with higher protein losses, which represents a major limitation in critically ill patients [18].

Most studies demonstrate that although daily solute clearances achieved with PD are lower than with daily intermittent hemodialysis, $\mathrm{PD}$ can provide adequate ultrafiltration rates and control of biochemical derangements in most pediatric patients. The fact that the peritoneal surface area (per unit weight) of infants is about twice that of an adult provides a major advantage for the pediatric population.

\section{Outcomes}

No prospective studies in children have evaluated the impact of the modality of dialysis in the outcome of patients with AKI in the ICU setting. A randomized study in critically ill adults with AKI comparing continuous venovenous hemodiafiltration with continuous PD showed that although hemodiafiltration provided higher urea and creatinine clearances, with faster correction of fluid overload, there were no differences in mortality or hemodynamic stability between the two modalities [19]. As a result, the decision about dialysis modality should be based on local expertise, resources available, and the patient's clinical status. The low technology environments encountered in developing countries makes PD the modality of choice for treatment of critically ill patients with AKI [20].

\section{Disclosure Statement}

The author has no conflicts of interest to disclose.

References

Blood Purif 2013;35:77-80
Williams DM, Sreedar SS, Mickell JJ, Chan JCM: Acute kidney failure: a pediatric experience over 20 years. Arch Pediatr Adolesc Med 2002;156:893-900.

2 Mishra OP, Gupta AK, Pooniya V, Prasad R, Tiwary NK, Schaefer F: Peritoneal dialysis in children with acute kidney injury: a developing country experience. Perit Dial Int 2012; 32:431-436.

3 Hui-Stickle S, Brewer ED, Goldstein SL: Pediatric ARF epidemiology at a tertiary care center from 1999 to 2001. Am J Kidney Dis 2005;45:96-101. 
-4 Zappitelli M, Bernier PL, Saczkowski RS, Tchervenkov CI, Gottesman R, Dancea A, Hyder A, Alkandari O: A small post-operative rise in serum creatinine predicts acute kidney injury in children undergoing cardiac surgery. Kidney Int 2009;76:885-892.

5 Samuels J, Ng CS, Nates J, Price K, Finkel K, Salahudeen A, Shaw A: Small increases in serum creatinine are associated with prolonged ICU stay and increased hospital mortality in critically ill patients with cancer. Support Care Cancer 2011;19:1527-1532.

6 Mammen C, Abbas AA, Skippen P, Nadel H, Levine D, Collet JP, Matsell DG: Long-term risk of CKD in children surviving episodes of acute kidney injury in the intensive care unit: a prospective cohort study. Am J Kidney Dis 2012;59:523-530.

-7 Sorof JM, Stromberg D, Brewer ED, Feltes TF, Fraser CD Jr: Early initiation of peritoneal dialysis after surgical repair of congenital heart disease. Pediatr Nephrol 1999;13: 641-645.

8 Bojan M, Gioanni S, Vouhé PR, Journois D, Pouard P: Early initiation of peritoneal dialysis in neonates and infants with acute kidney injury following cardiac surgery is associated with a significant decrease in mortality. Kidney Int 2012;82:474-481.
-9 Sutherland SM, Zappitelli M, Alexander SR, Chua AN, Brophy PD, Bunchman TE, Hackbarth R, Somers MJ, Baum M, Symons JM, Flores FX, Benfield M, Askenazi D, Chand D, Fortenberry JD, Mahan JD, McBryde K, Blowey D, Goldstein SL: Fluid overload and mortality in children receiving continuous renal replacement therapy: the prospective pediatric continuous renal replacement therapy registry. Am J Kidney Dis 2010;55: 316-325.

10 Warady BA, Bunchman T: Dialysis therapy for children with acute renal failure: survey results. Pediatr Nephrol 2000;15:11-13.

11 Flynn JT: Choice of dialysis modality for management of pediatric acute renal failure. Pediatr Nephrol 2002;17:61-69.

12 Chadha V, Warady BA, Blowey DL, Simckes AM, Alon US: Tenckhoff catheters prove superior to cook catheters in pediatric acute peritoneal dialysis. Am J Kidney Dis 2000; 35:1111-1116.

13 Auron A, Warady BA, Simon S, Blowey DL, Srivastava T, Musharaf G, Alon US: Use of the multipurpose drainage catheter for the provision of acute peritoneal dialysis in infants and children. Am J Kidney Dis 2007;49: 650-655.

14 Golej J, Kitzmueller E, Hermon M, Boigner H, Burda G, Trittenwein G: Low-volume peritoneal dialysis in 116 neonatal and paediatric critical care patients. Eur J Pediatr 2002;161:385-389.
15 Alarabi AA, Petersson T, Danielson BG, Wikström B: Continuous peritoneal dialysis in children with acute renal failure. Adv Perit Dial 1994;10:289-293.

16 Korbet S: Acute peritoneal dialysis prescription; in Daugirdas PB, Ing TS (eds): Handbook of Dialysis. Philadelphia, Lippincott Williams \& Wilkins, 2007, p 382.

17 McNiece KL, Ellis EE, Drummond-Webb JJ, Fontenot EE, O'Grady CM, Blaszak RT: Adequacy of peritoneal dialysis in children following cardiopulmonary bypass surgery. Pediatr Nephrol 2005;20:972-976.

18 Chitalia V, Almeida AF, Rai H, Bapat M, Chitalia KV, Acharya VN, Khanna R: Is peritoneal dialysis adequate for hypercatabolic acute renal failure in developing countries? Kidney Int 2002;61:747-757.

19 George J, Varma S, Kumar S, Thomas J, Gopi S, Pisharody R: Comparing continuous venovenous hemodiafiltraiton and peritoneal dialysis in critically ill patients with acute kidney injury: a pilot study. Perit Dial Int 2011;31:422-429.

20 Carter M, Kilonzo K, Odiit A, Kalyesubula R, Kotanko P, Levin N, Callegari J: Acute peritoneal dialysis treatment programs for countries of the East African community. Blood Purif 2012;33:149-152. 